Research Article

\title{
Comparison of Efficacy of Self-Expandable Metallic Stent Placement in the Unresectable Esophageal Cancer Patients
}

\author{
Masaya Uesato, Yasunori Akutsu, Kentarou Murakami, Yorihiko Muto, Akiko Kagaya, \\ Akira Nakano, Mizuho Aikawa, Tomohide Tamachi, Takahiro Arasawa, Hiroyuki Amagai, \\ Yasuhide Muto, and Hisahiro Matsubara
}

Department of Frontier Surgery, Chiba University Graduate School of Medicine, Chiba-shi, Chiba 260-8670, Japan

Correspondence should be addressed to Masaya Uesato; uesato@faculty.chiba-u.jp

Received 21 March 2017; Accepted 3 July 2017; Published 27 July 2017

Academic Editor: Yusuke Sato

Copyright ( 2017 Masaya Uesato et al. This is an open access article distributed under the Creative Commons Attribution License, which permits unrestricted use, distribution, and reproduction in any medium, provided the original work is properly cited.

\begin{abstract}
This is a retrospective study to evaluate the prevention of complications of metallic stent placement in patients with unresectable advanced esophageal cancer. A total of 87 patients were treated with 4 types of metal stents in the esophagus over a period of 18 years. Stent placement was technically successful. The most common prior treatment was chemoradiotherapy. There were no significant differences in the rate of patients with no complications among the prior treatments. Approximately, 30\% of patients had the most common chest pain in complications. Stent placement within one month after the completion of chemoradiotherapy should be avoided for the prevention of the chest pain. There was no significant difference in the rate of patients with no complications by lesion location. The rate of no complications was higher for the Niti-S stent than the Gianturco Z-stent or Ultraflex stent. Of note, no complications were noted for the Niti-S ultrathin stent at all. Among cases of stent-related death, the most common type of complication was respiratory disorder caused by the stent that seems to be thick and hard. Therefore, the stent with thin and flexible characteristics like the Niti-S ultrathin stent will solve the various problems of esophageal stent placement.
\end{abstract}

\section{Introduction}

Self-expandable metallic stent (SEMS) placement is used widely for the palliative treatment of unresectable malignant esophageal stricture [1-3]. Complications were reported at rates ranging from $36 \%-40 \%$ [4]. In particular, major complications such as hemorrhaging, perforation, fistula, a fever, and aspiration pneumonia have been reported to occur in $22 \%$ of cases [4]. Although several researchers [5-9] have reported that previous radiotherapy (RT) and chemotherapy are associated with an increased risk of life-threatening complications, other researchers $[10,11]$ have reported no relationship of life-threatening complications and these therapies.

We have placed SEMSs in patients with esophageal cancer over a period of approximately 20 years. Therefore, we examined their data, retrospectively, and would like to recommend the prevention of complications based on many experiences of metallic stent placement in patients with unresectable esophageal cancer.

\section{Materials and Methods}

2.1. Patients. A total of 87 patients were treated with a metal stent in the esophagus from December 1997 to April 2015 at the Chiba University Graduate School of Medicine. Data from these patients were collected retrospectively. The poststented follow-up period was ranged 2-153 days, mean 59.3 days, and median 52 days. A tumor was considered inoperable if the patient had distant metastasis, local tumor infiltration in neighboring organs, or a poor health condition. The expected average prognosis was around three months. We excluded patients who were scheduled to undergo future treatment, were not expected to be able to eat again, had recurrent nerve paralysis, or had a tumor growth within $2 \mathrm{~cm}$ of the upper esophageal sphincter. 
Furthermore, because the esophagus after stent insertion does not move peristaltically, we excluded any patients who were unable to sit up.

All patients were evaluated before stent placement and at discharge. Furthermore, we performed evaluations by interviewing the patients' family about the following items: (1) ability to eat and/or swallow (graded as 0 , normal swallowing; 1 , able to swallow some but not all solids; 2 , able to swallow semisolids; 3 , able to swallow fluids only; 4 , unable to swallow fluids [12]); (2) specific symptoms, such as chest pain, nausea, hiccup, and reflux; and (3) complications, such as recurrent dysphagia, stent migration, hemorrhaging, perforation, airway narrowing, aspiration pneumonia, and respiratory failure. Chest pain was defined as patients begin to use analgesics within a few days after stent placement or increase their use. The relationship of the specific symptoms, complications and prior treatment, location of lesion, and the types of SEMS was examined. We also evaluated the number of stent-related deaths within one month after placement.

2.2. Stent Placement and Choice. During stent insertion, all patients were consciously sedated with midazolam and pentazocine. The upper tumor margin was marked with an endoscopic hemoclip confirmed by radioscopy. A guidewire was inserted into the esophagus. A catheter for endoscopic retrograde cholangiopancreatography was inserted over the guidewire. The length of stricture was measured under radioscopy. The stents were advanced over the guidewire into the esophagus. The stricture was never dilated with a dilator such as a balloon. If the delivery system of the stent was unable to pass the tumor, the stent was covered with a polyvinyl chloride tube to make the axis stronger.

Four types of stent were used. We actually confirmed the feel of many kinds of stents released, and the tenderest stent was chosen in the time. The characteristics of the Gianturco Z-stent (Z stent), Ultraflex stent (UF stent), Niti-S stent (NS stent) (Figure 1), and Niti-S ultrathin stent (NSu stent) (Figure 2) are shown in Table 1. The NSu stent was inserted into the cervical or upper thoracic esophagus, which overlapped with trachea.

2.3. Statistical Analyses. Fisher's exact test was used to evaluate the differences in the proportions between the groups after chemoradiotherapy (CRT). The statistical analyses were conducted using the SPSS 15.0 software package (SPSS Inc., Chicago, IL, USA). $P$ values of less than 0.05 were considered to be statistically significant.

\section{Results}

The patient characteristics are outlined in Table 2. Of the 87 analyzed patients, 79 (90.8\%) were male, and the median age was 66.9 years (range $39-87$ years). The reasons for stent placement were stenosis/fistula: 63 (72.4\%)/24 (27.6\%) patients. The most common prior treatment was CRT, in 51 patients $(58.6 \%)$. Stent placement was technically successful in 91/93 times (97.8\%) among 87 patients. The stent-instent after regrowth was performed in four patients. Twice stent-in-stent was done in one patient.

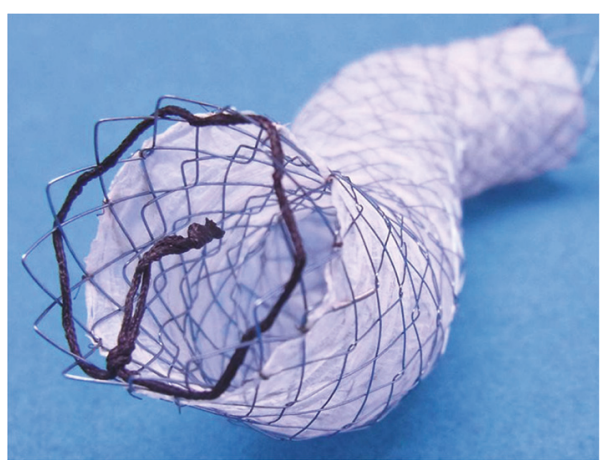

Figure 1: Partially covered Niti-S stent (Taewoong Medical) $10 \mathrm{~cm}$ long with a diameter of $16 \mathrm{~mm}$. The partially covered stent is uncovered at both ends over a distance of $0.5 \mathrm{~cm}$. This stent is able to maintain a three-dimensional form.

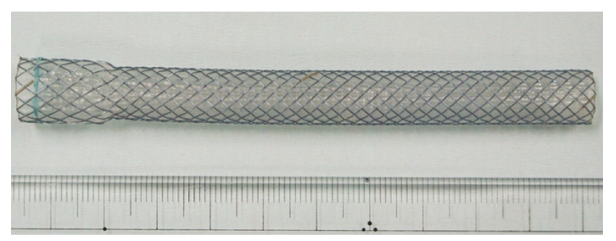

FIgURE 2: Fully covered Niti-S ultrathin stent (Taewoong Medical) $10 \mathrm{~cm}$ long with diameters of $12 \mathrm{~mm}$ (proximal) and $10 \mathrm{~mm}$ (middle-distal).

The changes in the oral alimentation status of the patients are shown by dysphagia score in Table 3. The mean improvement score (preplacement dysphagia score-postplacement dysphagia score) was 1.64. The best improvement score was 2, for the NS stent. The relationship between complications and prior treatment is shown in Table 4. There were no significant differences in patients with no complications by prior treatment except for RT. Approximately, 30\% of patients had the most common chest pain in complications. Only one case of a serious complication after the CRT was noted (perforation). The relationships of chest pain and the period from CRT (60 Gy) completion to stent insertion are shown in Table 5. Chest pain occurred in more patients within 30 days of stent placement than above 61 days after placement $(P=0.063)$. The relationships between complications and the lesion location are shown in Table 6. There were no significant differences in patients with no complications by the lesion location. Gastroesophageal reflux was confirmed in 5 cases (17.2\%) in the lower thoracic and abdominal esophagus. The relationships of the complications and the type of SEMS are shown in Table 7. The rate of no complication with NS stents $(77.8 \%)$ was higher than that with Z (41.2\%) or UF stents (43.4\%). Of note, there were no complications with NSu stents. The stent-related mortalities within one month are shown in Table 8. The most frequent type of complication was respiratory disorder.

\section{Discussion}

Although this study is retrospective, a lot of countermeasures have been revealed for safe and effective esophageal stent 
TABLE 1: Self-expandable metallic stent characteristics.

\begin{tabular}{lccc}
\hline Characteristics & Gianturco Z-stent & Ultraflex stent & Niti-S stent \\
\hline Products & Cook Medical Co., Denmark & Boston Scientific Co., Ireland & Taewoong Medical Co., Korea \\
Material & Stainless & Nitinol & Nitinol \\
Membrane material & Polyethylene & Polyethylene & Polytetrafluoroethylene \\
Outside diameter (mm) & 18 & 17 & $18,16,10$ (NSu stent) \\
Major axis (mm) & $100,120,140$ & 100,150 & $80,100,120,150$ \\
Delivery system diameter (Fr) & 24 & 24 & 16.5 \\
Shortening (\%) & None & 70 & 70 \\
Softness & - & ++ & +++ \\
Extended force & +++ & ++ & + \\
Visibility & Good & Good & Good \\
Justification & Impossible & Possible & Possible \\
Removed & Impossible & Possible within 2 weeks & Possible within 2 weeks \\
\hline
\end{tabular}

+: mild; ++: moderate; +++: severe.

TABle 2: Patient and tumor characteristics.

\begin{tabular}{|c|c|}
\hline Characteristics & \\
\hline \multicolumn{2}{|l|}{ Gender $(n)$} \\
\hline Male & 79 \\
\hline Female & 8 \\
\hline \multicolumn{2}{|l|}{ Age $(n)$} \\
\hline Range & $39-87$ \\
\hline Median & 66.9 \\
\hline \multicolumn{2}{|l|}{ Tumor site $(n)$} \\
\hline $\mathrm{Ce}, \mathrm{Ut}$ & 12 \\
\hline Mt & 47 \\
\hline $\mathrm{Lt}, \mathrm{Ae}$ & 28 \\
\hline \multicolumn{2}{|l|}{ Prior treatment ${ }^{*}$} \\
\hline None & 14 \\
\hline CRT & 51 \\
\hline RT & 1 \\
\hline CT & 23 \\
\hline Others & 16 \\
\hline \multicolumn{2}{|c|}{ Reason for unresection ${ }^{*}$} \\
\hline $\mathrm{T} 4^{\star *}$ & 45 \\
\hline $\mathrm{N} 3, \mathrm{~N} 4^{\text {** }}$ & 24 \\
\hline$M 1^{\circledast *}$ & 18 \\
\hline Poor condition & 23 \\
\hline Rejection & 1 \\
\hline \multicolumn{2}{|c|}{ Reason for insertion } \\
\hline Stenosis & 63 \\
\hline Fistula & 24 \\
\hline
\end{tabular}

Ce: cervical esophagus; Ut: upper thoracic esophagus; Mt: middle thoracic esophagus; Lt: lower thoracic esophagus; Ae: abdominal esophagus; CRT: chemoradiotherapy; RT: radiotherapy; CT: chemotherapy. ${ }^{*}$ There is some overlap; ${ }^{* *}$ Japanese Classification of Esophageal Cancer [26].

placement. Stent placement within one month after the completion of CRT should be avoided for the prevention of the chest pain. Death soon after stent placement had a strong
TABLE 3: Improvement in the dysphagia score (mean $\pm S D$ ).

\begin{tabular}{lcccc}
\hline Stent & $\begin{array}{c}\text { Number of } \\
\text { times }\end{array}$ & Prescore & Postscore & $\begin{array}{c}\text { Improvement } \\
\text { score }\end{array}$ \\
\hline $\mathrm{Z}$ & 17 & $3.65 \pm 0.49$ & $2.35 \pm 1.22$ & 1.3 \\
$\mathrm{UF}$ & 53 & $3.21 \pm 0.95$ & $1.45 \pm 1.2$ & 1.76 \\
$\mathrm{NS}$ & 18 & $4 \pm 0.57$ & $2 \pm 1.11$ & 2 \\
$\mathrm{NSu}$ & 3 & 4 & $2.67 \pm 0.58$ & 1.33 \\
Total & 91 & $3.43 \pm 0.82$ & $1.79 \pm 1.25$ & 1.64 \\
\hline Z: Cook-Z stent; UF: Ultraflex stent; NS: Niti-S stent; NSu: Niti-S ultrathin \\
stent; Improvement score = prescore minus postscore.
\end{tabular}

relationship with respiratory complications. To prevent such complications, an ultrathin stent might be best.

SEMS placement is used widely for the palliative treatment of unresectable malignant esophageal stricture [1-3]. Major complications such as hemorrhaging, perforation, fistula, a fever, and aspiration pneumonia occurred in $22 \%$ of subjects [4]. Therefore, the implementation of esophageal SEMSs has been sluggish. However, we have achieved good results without many serious complications at our institution. Chest pain is the most frequent complication, accounting for about $30 \%$ of patients. There is no predictive method of chest pain, but the preventive prescription of analgesia is performed now as in other reports [13].

The stent-related deaths occurred in patients who died within one month after insertion. All cases including a patient that occurred pneumothorax after esophageal perforation had respiratory disorders. Two patients who had complications just after stent insertion used the $\mathrm{Z}$ stent with high radial and axial forces. Moreover, two cases using $Z$ stent suffered from respiratory failure. The rapid increase of the right pleural effusion was pointed out. Therefore, there may have been damage to the thoracic duct. Generally, stents with strong expansion and a wide lumen are deemed suitable. However, such stents can cause many severe complications [4]. In our study, the ratio of stent-related complications was low, due in part to our use of NS stents. NS stents have several characteristics that make them promising, such as 
TABLE 4: Relationships between complications and prior treatment ( $n=91$ times, number (\%)).

\begin{tabular}{|c|c|c|c|c|c|}
\hline & $\begin{array}{l}\text { None } \\
n=13\end{array}$ & $\begin{array}{l}\text { CRT }^{*} \\
n=51\end{array}$ & $\begin{array}{c}\mathrm{RT} \\
n=1\end{array}$ & $\begin{array}{c}\mathrm{CT}^{*} \\
n=23\end{array}$ & $\begin{array}{c}\text { Others }^{*} \\
n=16\end{array}$ \\
\hline Chest pain ${ }^{*}$ & $2(15.4)$ & $15(29.4)$ & $1(100)$ & $8(34.8)$ & $4(25.0)$ \\
\hline Nausea* $^{*}$ & 0 & $1(2.0)$ & 0 & $1(4.3)$ & 0 \\
\hline Hiccup $^{*}$ & 0 & $1(2.0)$ & 0 & $1(4.3)$ & 0 \\
\hline Gastroesophageal reflux ${ }^{*}$ & $2(15.4)$ & 0 & 0 & $2(8.7)$ & 0 \\
\hline Recurrent dysphagia ${ }^{*}$ & $2(15.4)$ & $1(2.0)$ & 0 & $1(4.3)$ & $1(6.3)$ \\
\hline Stent migration ${ }^{*}$ & 0 & $1(2.0)$ & 0 & 0 & 0 \\
\hline Hemorrhaging ${ }^{*}$ & 0 & 0 & 0 & $1(4.3)$ & 0 \\
\hline Perforation $^{*}$ & $1(7.7)$ & $1(2.0)$ & 0 & 0 & 0 \\
\hline Airway narrowing ${ }^{*}$ & $1(7.7)$ & 0 & 0 & 0 & $1(6.3)$ \\
\hline Aspiration pneumonia* & 0 & 0 & 0 & $1(4.3)$ & 0 \\
\hline Respiratory failure & $1(7.7)$ & $1(2.0)$ & 0 & 0 & 0 \\
\hline None & $6(46.2)$ & $27(52.9)$ & 0 & $13(56.5)$ & $9(56.3)$ \\
\hline
\end{tabular}

CRT: chemoradiotherapy; RT: radiotherapy; CT: chemotherapy. ${ }^{*}$ There is some overlap.

TABLE 5: Relationships of the chest pain and the period from chemoradiotherapy (60 Gy) completion to stent insertion $(n=20$ patients).

\begin{tabular}{|c|c|c|c|}
\hline $\begin{array}{l}\text { Period from CRT } \\
\text { to insertion (days) }\end{array}$ & $1-30$ & $31-60$ & 61 and above \\
\hline \multicolumn{4}{|l|}{ Gender } \\
\hline Male & 6 & 4 & 10 \\
\hline Female & 0 & 0 & 0 \\
\hline \multicolumn{4}{|l|}{ Age } \\
\hline Median & 64.8 & 64.6 & 65.9 \\
\hline \multicolumn{4}{|l|}{ Tumor location } \\
\hline Ce, Ut & 2 & 0 & 2 \\
\hline $\mathrm{Mt}$ & 3 & 3 & 5 \\
\hline $\mathrm{Lt}, \mathrm{Ae}$ & 1 & 1 & 3 \\
\hline \multicolumn{4}{|c|}{ Reason for intubation } \\
\hline Stenosis & 5 & 2 & 7 \\
\hline Fistula & 1 & 2 & 3 \\
\hline \multicolumn{4}{|l|}{ Type of SEMS } \\
\hline $\mathrm{Z}$ & 2 & 1 & 1 \\
\hline UF & 4 & 3 & 8 \\
\hline NS & 0 & 0 & 1 \\
\hline Chest pain (\%) & $5 / 6(83.3)^{*}$ & $2 / 4(50.0)$ & $3 / 10(30.0)^{*}$ \\
\hline
\end{tabular}

CRT: chemoradiotherapy; Ce: cervical esophagus; Ut: upper thoracic esophagus; Mt: middle thoracic esophagus; Lt: lower thoracic esophagus; Ae: abdominal esophagus; Z: Cook-Z stent; UF: Ultraflex stent; NS: Niti-S stent; ${ }^{*} P=0.063$

their ultrathin size, low radial force [14], moderate axial force [14], and thin delivery system. Of note, no other stent had a low axial force in our study. If the tumor has infiltrated neighboring organs, the esophageal axis often cannot maintain a straight line. Figure 1 shows that NS stents can maintain axial flexure. In addition, NS stents do not apply high power to such flexure. Therefore, we generally opt for the NS stent. Two cases had tumors located in the cervical or
TABLE 6: Relationships of complications and lesion location $(n=91$ times, number (\%)).

\begin{tabular}{lccc}
\hline & $\begin{array}{c}\mathrm{Ce}, \mathrm{Ut} \\
n=12\end{array}$ & $\begin{array}{c}\mathrm{Mt} \\
n=50\end{array}$ & $\begin{array}{c}\mathrm{Lt}, \mathrm{Ae} \\
n=29\end{array}$ \\
\hline Chest pain $^{*}$ & $4(33.3)$ & $16(32.0)$ & $8(27.6)$ \\
Nausea $^{*}$ & 0 & $2(4.0)$ & 0 \\
Hiccup $^{*}$ & $2(16.7)$ & 0 & 0 \\
Gastroesophageal reflux $^{*}$ & $1(8.3)$ & $4(8.0)$ & $5(17.2)$ \\
Recurrent dysphagia $^{*}$ & 0 & $4(8.0)$ & $1(3.4)$ \\
Stent migration $^{*}$ & 0 & 0 & $1(3.4)$ \\
Hemorrhage $^{*}$ & 0 & $1(2.0)$ & 0 \\
Perforation $^{*}$ & 0 & $1(2.0)$ & $1(3.4)$ \\
Airway narrowing $^{*}$ & $1(16.7)$ & $1(2.0)$ & 0 \\
Aspiration pneumonia $^{*}$ & 0 & 0 & $1(3.4)$ \\
Respiratory failure $^{*}$ & 0 & $2(4.0)$ & 0 \\
None $^{\text {Ce: cerican }}$ & $6(50.0)$ & $27(54.0)$ & $14(48.3)$ \\
\hline
\end{tabular}

Ce: cervical esophagus; Ut: upper thoracic esophagus; Mt: middle thoracic esophagus; Lt: lower thoracic esophagus; Ae: abdominal esophagus. ${ }^{{ }^{*}}$ There is some overlap.

upper-middle thoracic portion and died of airway narrowing. The outside diameter of the general esophageal SEMSs is known to be $18 \mathrm{~mm}$. Large-diameter stents reduce the risk of recurrence dysphagia due to stent migration, tissue overgrowth, or food obstruction. Increasing the diameter, however, increases the risk of stent-related complications [4]. Questions remain as to whether or not this size is appropriate in Japanese patients. If a stent is inserted in the cervical or upper thoracic, or middle thoracic portion, we must consider the risk of the trachea being pressed. The distance from the trachea to the vertebra should be confirmed by computed tomography beforehand. We further suggest that NSu stents be used (Figure 2). We imported NSu stents into Japan for the first time and began using them in our patients. Figure 3(a) shows a case of a tumor in the upper thoracic 
TABLE 7: Relationships of complications and types of SEMS ( $n=91$ times, number (\%)).

\begin{tabular}{|c|c|c|c|c|}
\hline & $\begin{array}{c}\mathrm{Z} \\
n=17\end{array}$ & $\begin{array}{c}\text { UF } \\
n=53\end{array}$ & $\begin{array}{c}\text { NS } \\
n=18\end{array}$ & $\begin{array}{l}\text { NSu } \\
n=3\end{array}$ \\
\hline Chest pain ${ }^{*}$ & $6(35.3)$ & $20(37.7)$ & $2(11.1)$ & 0 \\
\hline Nausea* $^{*}$ & 0 & $2(3.8)$ & 0 & 0 \\
\hline Hiccup ${ }^{*}$ & 0 & $2(3.8)$ & 0 & 0 \\
\hline Gastroesophageal reflux ${ }^{*}$ & $2(11.8)$ & $8(15.1)$ & 0 & 0 \\
\hline Recurrent dysphagia* & 0 & $4(7.5)$ & $1(5.6)$ & 0 \\
\hline Stent migration ${ }^{*}$ & $1(5.9)$ & 0 & 0 & 0 \\
\hline Hemorrhaging ${ }^{*}$ & 0 & $1(1.9)$ & 0 & 0 \\
\hline Perforation ${ }^{*}$ & $1(5.9)$ & 0 & $1(5.6)$ & 0 \\
\hline Airway narrowing ${ }^{*}$ & 0 & $3(5.7)$ & 0 & 0 \\
\hline Aspiration pneumonia ${ }^{*}$ & 0 & $1(1.9)$ & 0 & 0 \\
\hline Respiratory failure & $2(11.8)$ & 0 & 0 & 0 \\
\hline None & $7(41.2)$ & $23(43.4)$ & $14(77.8)$ & $3(100)$ \\
\hline
\end{tabular}

Z: Cook-Z stent; UF: Ultraflex stent; NS: Niti-S stent; NSu: Niti-S ultrathin stent. ${ }^{*}$ There is some overlap.

TABLE 8: Stent-related fatal cases.

\begin{tabular}{|c|c|c|c|c|c|c|c|c|c|}
\hline $\begin{array}{l}\text { Age } \\
\text { (years) }\end{array}$ & Gender & Location & $\mathrm{T} 4$ & $\begin{array}{c}\text { Reason for } \\
\text { insertion }\end{array}$ & $\begin{array}{l}\text { Type of } \\
\text { SEMS }\end{array}$ & Pretreatment & $\begin{array}{c}\text { Periods to } \\
\text { complication }\end{array}$ & Complications & $\begin{array}{c}\text { Periods from insertion } \\
\text { to death (days) }\end{array}$ \\
\hline 85 & Male & $\mathrm{Mt}, \mathrm{Lt}$ & None & Stenosis & $\mathrm{Z}$ & None & $\begin{array}{c}\text { During } \\
\text { insertion }\end{array}$ & Perforation & 2 \\
\hline 49 & Female & Mt & None & Stenosis & $\mathrm{Z}$ & CRT (40 Gy) & 8 hours & $\begin{array}{l}\text { Respiratory } \\
\text { failure }\end{array}$ & 6 \\
\hline 68 & Male & $\mathrm{Lt}, \mathrm{Ae}$ & None & Stenosis & UF & $\mathrm{CT}$ & 1 day & $\begin{array}{l}\text { Aspiration } \\
\text { pneumonia }\end{array}$ & 22 \\
\hline 81 & Male & $\mathrm{Ce}$ & Trachea & Stenosis & UF & CRT (65 Gy), GT & 3 days & Airway narrowing & 25 \\
\hline 61 & Male & Ut, Mt & Trachea & Fistula & UF & None & 15 days & Airway narrowing & 22 \\
\hline
\end{tabular}

Ce: cervical esophagus; Ut: upper thoracic esophagus; Mt: middle thoracic esophagus; Lt: lower thoracic esophagus; Ae: abdominal esophagus; Z: Cook-Z stent; UF: Ultraflex stent; CRT: chemoradiotherapy; CT: chemotherapy; GT: genetherapy.

portion. After the placement of a $10 \mathrm{~mm} \mathrm{NSu}$ stent, the membranous portion of the trachea did not transform (Figure 3(b)). A thin and soft stent like NSu stent will reduce the risk of compressing the tracheal membranous portion and might be best to prevent respiratory complications. Patients with esophageal cancer stenosis or fistel retain the hope of continuing to eat normally. However, the dysphagia improvement score with NSu stents was 1.33. Therefore, such patients will be not able to eat all meals in the usual way. However, the salivary deglutition is improved following the procedure, and the patients' quality of life is markedly improved as well. Gastroesophageal reflux was observed in 5 cases $(5 / 29 ; 17.2 \%)$ of lower thoracic and abdominal portion. One of these patients died of aspiration pneumonia. Unfortunately, no stent with an antireflux valve has been marketed. This complication can now be avoided [15].

It might be very important not to dilate the stenosis using a balloon before stent insertion. When an esophageal stent is inserted, such as a UF stent, prior dilation is generally performed with a 10 to $18 \mathrm{~mm}$ balloon $[16,17]$. However, several researchers $[4,18]$ recommend that prior dilation to more than $12 \mathrm{~mm}$ or 7-8 $\mathrm{mm}$ in a single session and too-quick dilation be avoided. We experienced one fatal case due to esophageal perforation caused by $8 \mathrm{~mm}$ balloon dilation $[19,20]$.
Therefore, we deemed expansion by a balloon unfavorable and did not always perform it with UF and NS stenting. If the delivery system could not pass through a severe stenosis, an overtube was used to cover the system to prevent axial arcuation and enable us to pass the system. Its flexibility makes the system difficult to pass through the stenosis. There is a report [21] that revealed the usefulness of stent placement using an overtube for malignant gastroduodenal obstructions. Our idea involves the same method of preventing flexure in the greater curvature as in that study. On the placement, however, we had two unsuccessful patients. The first patient was inserted the next stent into the mesh portion of the prior stent during the stent-in-stent. The second patient was a failure because we could not recognize that the guidewire was inserted outside the wall.

Regardless of previous treatment, about $50 \%$ of patients who underwent esophageal stent placement suffered complications in our study. The use of SEMSs in patients with prior RT is strictly limited [5-9]. Although RT to the esophagus has acute and late toxicity, the late effects of radiation are believed to be due to inflammation and scar formation within the esophageal musculature [22]. The late effects of RT are seen three or more months after completion of RT, with a median time to onset of six months $[23,24]$. Iwasaki et al. 


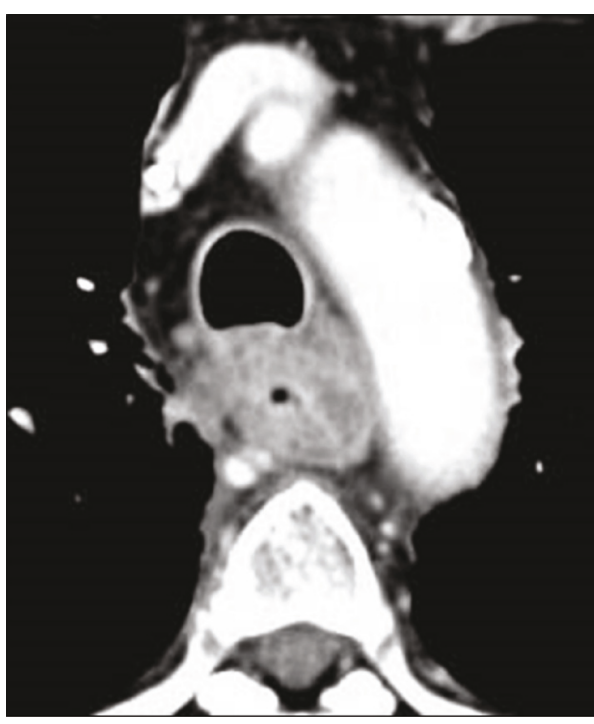

(a)

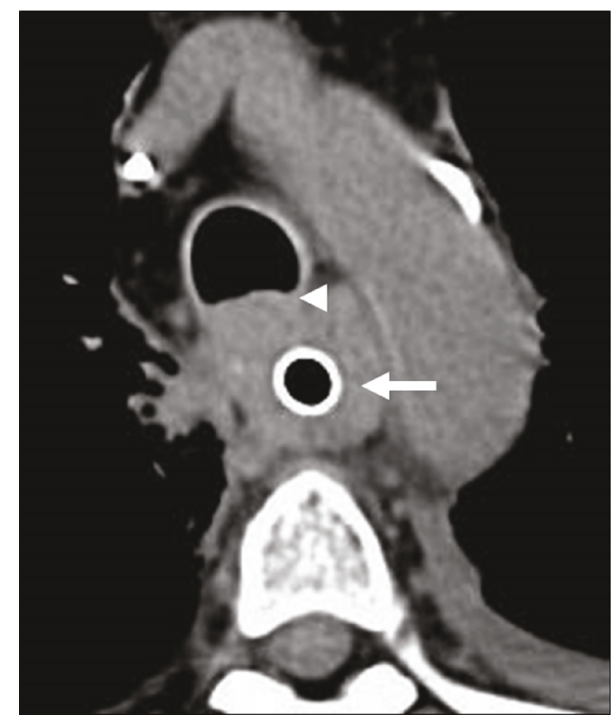

(b)

Figure 3: (a) CT findings before stent placement. Two months after chemoradiotherapy, the tumor located in the middle thoracic esophagus had invaded the trachea. (b) CT findings after Niti-S ultrathin stent placement (arrow). The membranous portion of the trachea did not transform (arrowhead).

[25] reported that the late effects of esophageal RT have an important role in the occurrence of severe stent-related complications. In our study, the mean observation period was 59.3 days. Furthermore, our criterion regarding stent placement is a prognosis of around three months, which may have prevented our experience of a high rate of late effects. In the acute phase, chest pain occurred in more patients with less than 30 days between CRT completion and stent insertion than in those with more than 61 days' interval. The acute effects of radiation are thought to be due to temporary inflammation such as ulcer and erosion. Moreover, the interaction between radiation and chemotherapy affects the severity of esophagitis [22]. Therefore, stent placement within one month after the completion of CRT should be avoided.

This study has several limitations. It was a retrospective study performed in a single institution. The stent placement was done for only patients with a prognosis of three months or less. In an additional investigation, 63.2\% (55/87) of patients could be followed and the 3-month survival rate was $34.5 \%(19 / 55)$. We believe that the expected prognosis was not significantly different from the reality. However, the applications of esophageal SEMS placement should be further clarified in large, prospective studies.

\section{Conclusions}

In this study, a lot of problems associated with metallic stents in patients with unresectable advanced esophageal cancer were revealed. However, we suggest that the stent with thin and flexible characteristics like the Niti-S ultrathin stent will solve the various problems of esophageal stent placement. If the stent placement in patients with prior CRT is performed, the placement within one month after the completion of CRT should be avoided for the prevention of the chest pain.

\section{Abbreviations \\ SEMS: $\quad$ Self-expandable metallic stent \\ RT: $\quad$ Radiotherapy \\ Z stent: Gianturco Z-stent \\ UF stent: Ultraflex stent \\ NS stent: Niti-S stent \\ NSu stent: Niti-S ultrathin stent \\ CRT: $\quad$ Chemoradiotherapy.}

\section{Consent}

Patients were not required to give their informed consent for the study because the analysis used anonymous clinical data that were obtained after each patient agreed to treatment with their written consent.

\section{Conflicts of Interest}

The authors declare no conflicts of interest for this article.

\section{References}

[1] A. Mao, "Interventional therapy of esophageal cancer," Gastrointestinal Tumors, vol. 3, no. 2, pp. 59-68, 2016.

[2] M. C. Spaander, T. H. Baron, P. D. Siersema et al., "Esophageal stenting for benign and malignant disease: European Society of Gastrointestinal Endoscopy (ESGE) Clinical Guideline," Endoscopy, vol. 48, no. 10, pp. 939-948, 2016.

[3] H. Kuwano, Y. Nishimura, T. Oyama et al., "Guidelines for diagnosis and treatment of carcinoma of the esophagus April 2012 edited by the Japan Esophageal Society," Esophagus, vol. 12, pp. 1-30, 2015.

[4] E. M. Verschuur, E. W. Steyerberg, E. J. Kuipers, and P. D. Siersema, "Effect of stent size on complications and recurrent dysphagia in patients with esophageal or gastric cardia 
cancer," Gastrointestinal Endoscopy, vol. 65, no. 4, pp. 592601, 2007.

[5] H. K. Na, H. Y. Song, J. H. Kim et al., "How to design the optimal self-expandable oesophageal metallic stents: 22 years of experience in 645 patients with malignant strictures," European Radiology, vol. 23, no. 3, pp. 786-796, 2013.

[6] J. Y. Park, J. H. Shin, H. Y. Song, S. Y. Yi, and J. H. Kim, "Airway complications after covered stent placement for malignant esophageal stricture: special reference to radiation therapy," AJR. American Journal of Roentgenology, vol. 198, no. 2, pp. 453-459, 2012.

[7] M. Muto, A. Ohtsu, Y. Miyata, Y. Shioyama, N. Boku, and S. Yoshida, "Self-expandable metallic stents for patients with recurrent esophageal carcinoma after failure of primary chemoradiotherapy," Japanese Journal of Clinical Oncology, vol. 31, no. 6, pp. 270-274, 2001.

[8] G. Qiu, Y. Tao, X. Du et al., "The impact of prior radiotherapy on fatal complications after self-expandable metallic stents (SEMS) for malignant dysphagia due to esophageal carcinoma," Diseases of the Esophagus, vol. 26, no. 2, pp. 175-181, 2013.

[9] K. J. Kinsman, B. T. DeGregorio, R. M. Katon et al., "Prior radiation and chemotherapy increase the risk of life-threatening complications after insertion of metallic stents for esophagogastric malignancy," Gastrointestinal Endoscopy, vol. 43, no. 3, pp. 196-203, 1996.

[10] I. Raijman, I. Siddique, and P. Lynch, "Does chemoradiation therapy increase the incidence of complications with selfexpanding coated stents in the management of malignant esophageal strictures?" The American Journal of Gastroenterology, vol. 92, no. 12, pp. 2192-2196, 1997.

[11] M. Y. Homs, B. E. Hansen, M. Blankensteinvan, J. Haringsma, E. J. Kuipers, and P. D. Siersema, "Prior radiation and/or chemotherapy has no effect on the outcome of metal stent placement for oesophagogastric carcinoma," European Journal of Gastroenterology \& Hepatology, vol. 16, no. 2, pp. 163-170, 2004.

[12] H. Neuhaus, W. Hoffmann, H. J. Dittler, H. P. Niedermeyer, and M. Classen, "Implantation of self-expanding esophageal metal stents for palliation of malignant dysphagia," Endoscopy, vol. 24, no. 25, pp. 405-410, 1992.

[13] A. N. Reijm, P. Didden, M. J. Bruno, and M. C. Spaander, "Early pain detection and management after esophageal metal stent placement in incurable cancer patients: a prospective observational cohort study," Endoscopy International Open, vol. 4, no. 8, pp. E890-E894, 2016.

[14] M. M. Hirdes, F. P. Vleggaar, M. Beulede, and P. D. Siersema, "In vitro evaluation of the radial and axial force of selfexpanding esophageal stents," Endoscopy, vol. 45, no. 12, pp. 997-1005, 2013.

[15] E. Coron, G. David, S. Lecleire et al., "Antireflux versus conventional self-expanding metallic stents (SEMS) for distal esophageal cancer: results of a multicenter randomized trial," Endoscopy International Open, vol. 4, no. 6, pp. E730-E736, 2016.

[16] I. Rozanes, A. Poyanli, and B. Acunas, "Palliative treatment of inoperable malignant esophageal strictures with metal stents: one center's experience with four different stents," European Journal of Radiology, vol. 43, no. 3, pp. 196-203, 2002.

[17] T. Sabharwal, M. S. Hamady, S. Chui, S. Atkinson, R. Mason, and A. Adam, "A randomised prospective comparison of the Flamingo Wallstent and Ultraflex stent for palliation of dysphagia associated with lower third oesophageal carcinoma," Gut, vol. 52, no. 7, pp. 922-926, 2003.

[18] E. Therasse, V. L. Oliva, E. Lafontaine, P. Perreault, M. F. Giroux, and G. Soulez, "Balloon dilation and stent placement for esophageal lesions: indications, methods, and results," Radiographics, vol. 23, no. 1, pp. 89-105, 2003.

[19] M. Uesato, K. Shuto, T. Kono et al., "Gradual tube dilation method before percutaneous endoscopic gastrostomy for obstructive esophageal cancer," Esophagus, vol. 13, pp. 6873, 2016.

[20] N. Takeshita, M. Uesato, K. Shuto et al., "A 3-step gradual dilation method: a new safe technique of percutaneous endoscopic gastrostomy for obstructive esophageal cancer," Surgical Laparoscopy, Endoscopy \& Percutaneous Techniques, vol. 24, pp. e140-e142, 2014.

[21] T. Ikeda, N. Ueda, Y. Yonemura et al., "Peroral placement of a self-expandable covered metallic stent using an overtube for malignant gastroduodenal obstructions," Surgery Today, vol. 41, no. 5, pp. 637-642, 2011.

[22] P. E. Newburger, J. R. Cassady, and N. Jaffe, "Esophagitis due to adriamycin and radiation therapy for childhood malignancy," Cancer, vol. 42, no. 2, pp. 417-423, 1978.

[23] L. R. Coia, R. J. Myerson, and J. E. Tepper, "Late effects of radiation therapy on the gastrointestinal tract," International Journal of Radiation Oncology, Biology, Physics, vol. 31, no. 5, pp. 1213-1236, 1995.

[24] Y. Dai, C. Li, Y. Xie et al., "Interventions for dysphagia in oesophageal cancer," Cochrane Database of Systematic Reviews, no. 10, article CD005048, 2014.

[25] H. Iwasaki, T. Mizushima, Y. Suzuki et al., "Factors that affect stent-related complications in patients with malignant obstruction of the esophagus or gastric cardia," Gut Liver, vol. 11, no. 1, pp. 47-54, 2016.

[26] Japan Esophageal Society, "Japanese classification of esophageal cancer, tenth edition: part I," Esophagus, vol. 6, pp. 1-25, 2009. 


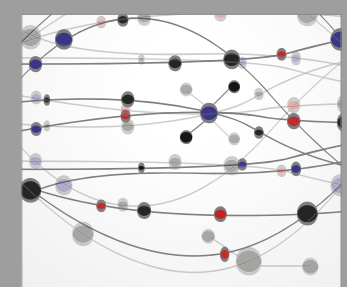

The Scientific World Journal
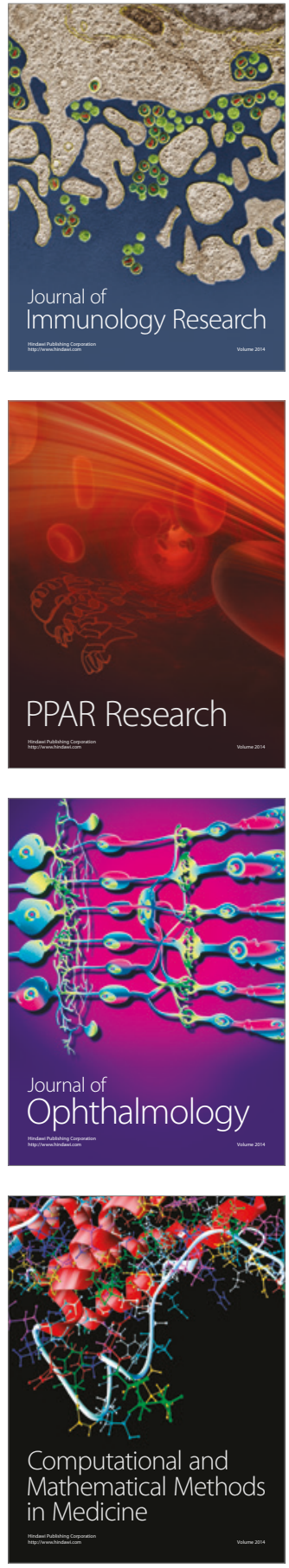

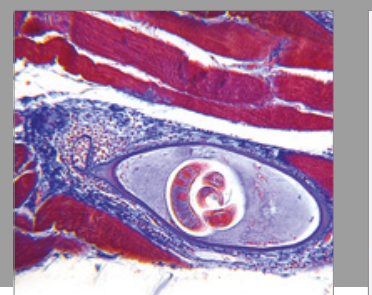

Gastroenterology Research and Practice
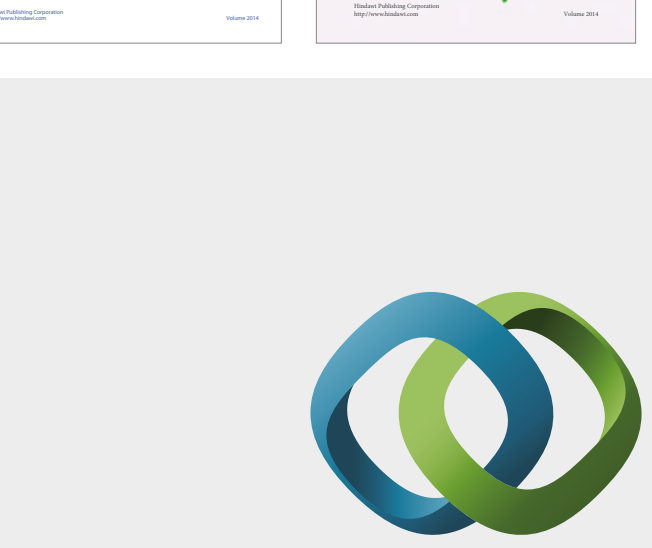

\section{Hindawi}

Submit your manuscripts at

https://www.hindawi.com
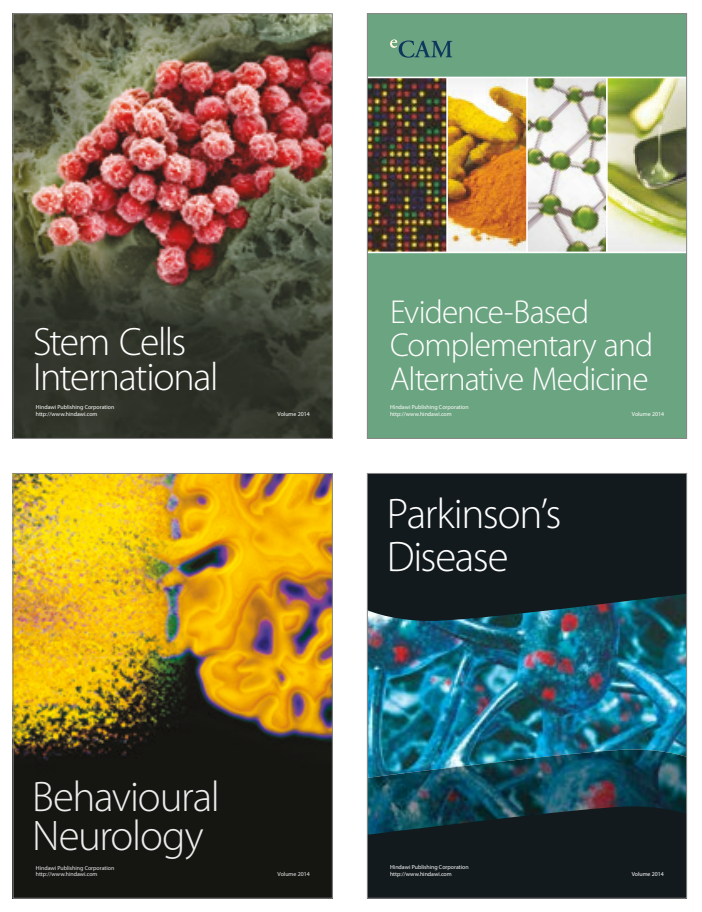
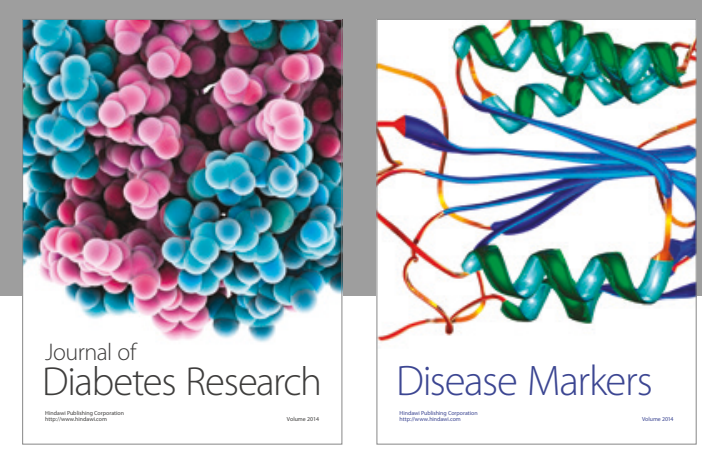

Disease Markers
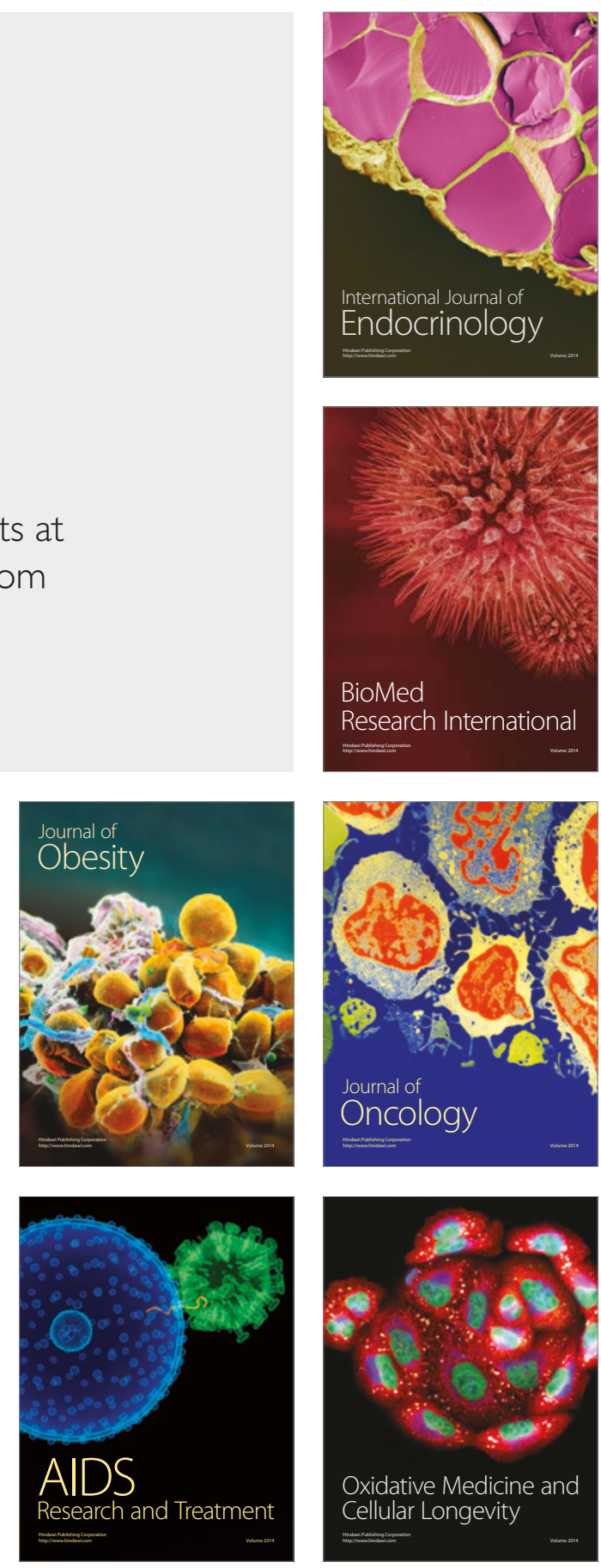